\title{
Influence of Nanoparticles and Graphite Foam on the Supercooling of Acetamide
}

\author{
Jia Yu, Xuan Chen, Xiaoliang Ma, Qingfei Song, Yukun Zhao, and Jiahao Cao \\ College of Aerospace and Civil Engineering, Harbin Engineering University, Harbin 150001, China \\ Correspondence should be addressed to Jiahao Cao; 1017874057@qq.com
}

Received 16 October 2014; Accepted 11 December 2014; Published 29 December 2014

Academic Editor: Ping Xiao

Copyright ( 2014 Jia Yu et al. This is an open access article distributed under the Creative Commons Attribution License, which permits unrestricted use, distribution, and reproduction in any medium, provided the original work is properly cited.

\begin{abstract}
Acetamide is a promising phase change materials (PCMs) for thermal storage,but the large supercooling during the freezing process has limited its application. In this study, we prepared acetamide- $\mathrm{SiO}_{2}$ composites by adding nano-SiO $\mathrm{Sinto}_{2}$ acetamide. This modified PCM was then impregnated into the porous graphite foam forming acetamide- $\mathrm{SiO}_{2}$-graphite foam form-stable composites. These composites were subjected to melting-solidification cycles 50 times; the time-temperature curves were tracked and recorded during these cycles. The time-temperature curves showed that, for the acetamide containing $2 \mathrm{wt} . \% \mathrm{SiO}_{2}$, the supercooling phenomenon was eliminated and the material's performance was stable for 50 cycles. The solidification temperature of the acetamide- $\mathrm{SiO}_{2}$-graphite foam samples was $65^{\circ} \mathrm{C}$ and the melting temperature was lowered to $65^{\circ} \mathrm{C}$. The samples exhibited almost no supercooling and the presence of $\mathrm{SiO}_{2}$ had no significant effect on the melting-solidification temperature. The microscopic supercooling of the acetamide- $\mathrm{SiO}_{2}$ composite was measured using differential scanning calorimetry (DSC). The results indicated that when the content of $\mathrm{SiO}_{2}$ was $1 \mathrm{wt}$. to $2 \mathrm{wt}$. \%, the supercooling could be reduced to less than $10^{\circ} \mathrm{C}$ and heat was sufficiently released during solidification. Finally, a set of algorithms was derived using MATLAB software for simulating the crystallization of samples based on the classical nucleation theory. The results of the simulation agreed with the experiment results.
\end{abstract}

\section{Introduction}

Among the available techniques suitable for storing thermal energy and for controlling temperature in systems subjected to periodic heating, the use of latent heat thermal storage technology has attracted considerable attention. In a latent heat thermal storage system, thermal energy is stored/controlled by using phase change materials (PCMs) in which a large amount of heat is absorbed or released during the phase change processes with only small temperature variations. This process allows for periodic heating, the conversion of temperature oscillations into melting interface oscillations and significant damping of the thermal perturbations. Phase change materials (PCMs), such as acetamide $\left(\mathrm{C}_{2} \mathrm{H}_{5} \mathrm{NO}\right)$, exhibit desirable properties, such as high latent heat of fusion and suitable melting temperature, which offer potential for thermal storage applications. The melting point of acetamide is $78^{\circ} \mathrm{C}$ and it can be expected to store waste energy from heat sources with temperatures over $70^{\circ} \mathrm{C}$. However, one feature of most PCMs is the supercooling characteristic and acetamide is no exception. It possesses a large degree of supercooling which was $39.3^{\circ} \mathrm{C}$ and which has been found by DSC testing. In acetamide PCMs, solidification does not occur at the melting point and the material assumes the supercooled state over a relatively wide temperature range. This seriously affects the subsequent endothermic melting process and causes failure in phase change thermal control applications. To initiate the solidification of the supercooled PCMs, nucleation inducement procedures are needed including the addition of nucleation catalysts, application of mechanical vibration, or ultrasonic irradiation [1-4]. Of these techniques, addition of nucleating agents is the most convenient, reliable, and economical one.

Many studies have shown that employing nanoparticles dispersed into the PCMs as a nucleating agent can significantly suppress supercooling. Mo et al. [5] investigated the supercooling of $\mathrm{TiO}_{2}$-water nanofluids and DI water and showed that the nanoparticles reduce the supercooling of the water by heterogeneous nucleation. In Lu et al. study [6], the effect of several nanomaterials ( $\mathrm{AlN}, \mathrm{Si}_{3} \mathrm{~N}_{4}, \mathrm{ZrB}_{2}, \mathrm{SiO}_{2}, \mathrm{BC}_{4}$, 
and $\mathrm{SiB}_{6}$ ) as nucleating agents for sodium acetate trihydrate (SAT) was investigated. The results showed that addition of 5 wt. $\%$ or 4 wt. $\% \mathrm{Si}_{3} \mathrm{~N}_{4}, 10$ wt. $\% \mathrm{ZrB}_{2}, 5$ wt. $\%$ AlN dispersed in SAT helped eliminate the supercooling of SAT. Specifically, 2 wt.\% ultrasonic dispersed nano- $\mathrm{SiO}_{2}$, premixed by magnetic stirring in the melted SAT, eliminated the supercooling of the SAT. Using three different types of $\mathrm{SiO}_{2}$ nanoparticles as the antisupercooling agents, Wu et al. [7] investigated the surface effect of the interaction between nanoparticle and hydrate salts during the phase changing process. Aerosol $\mathrm{SiO}_{2}$ exhibited the most effective and stable performance as nucleators for hydrate salts. Supercooling of hydrate salts was found to be easily suppressed by the nanoadditives, which have high specific surface area and strong polar hydroxyl bonds on the surface.

Most of the current studies have focused on hydrate salt PCMs and have ignored the organic PCMs. However, hydrate salts PCMs are inferior to the organic PCMs, because the former are easy to phase-separate in the phase change process [8]. In this paper, the supercooling of acetamide PCMs was researched. And the acetamide- $\mathrm{SiO}_{2}$ composites were prepared by adding nano- $\mathrm{SiO}_{2}$ into acetamide. Then, the acetamide- $\mathrm{SiO}_{2}$ composites were impregnated into porous graphite foam to form acetamide- $\mathrm{SiO}_{2}$-graphite foam samples (a type of thermal energy storage application [9]). The phase change properties of these materials were then established. Finally, we simulated the crystallization process of the experimental samples using MATLAB and found that the model agreed well with the experimental results.

\section{Experimental}

2.1. Materials and Methods. Acetamide $\left(\mathrm{C}_{2} \mathrm{H}_{5} \mathrm{NO}\right)$ with purity of $99 \%$ was used as the target material. $\mathrm{SiO}_{2}$ nanoparticles with the average diameter of $30 \mathrm{~nm}$ were chosen as the additive to be dispersed in acetamide. The melted acetamide and $\mathrm{SiO}_{2}$ were combined and magnetically stirred for $30 \mathrm{~min}$ with magnetic stirrer and then sonicated for $3 \mathrm{~h}$ to obtain a well-dispersed suspension. The acetamide- $\mathrm{SiO}_{2}$ composites were solidified at the room temperature and were used for this study. The graphite foam with porosity of $85 \%$ and average pore diameter of $400 \mathrm{um}$ (prepared using the template method, details references [10]) was infiltrated with the melted acetamide- $\mathrm{SiO}_{2}$ for $20 \mathrm{~min}$ to form acetamide$\mathrm{SiO}_{2}$-graphite foam. In this way, we prepared the samples with a content of $\mathrm{SiO}_{2}$ of $0 \mathrm{wt} . \%, 0.5 \mathrm{wt} . \%, 1 \mathrm{wt} . \%, 2 \mathrm{wt} . \%$, and $5 \mathrm{wt} . \%$, respectively.

2.2. Melting-Solidification Experiments. The thermal cycling behavior of each sample was determined using the apparatus shown in Figure 1. Testing was accomplished by placing the identical quantities of each sample in a beaker, a thermocouple was connected to the center of these samples, and a data acquisition module collected temperature data to a computer in real time. Samples were solidified at room temperature and then placed in the incubator at $110^{\circ} \mathrm{C}$ to melt them. This procedure was repeated for 50 cycles.

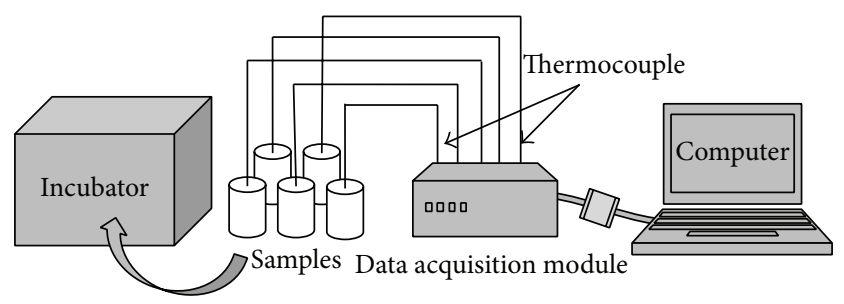

FIGURE 1: Schematic of melting-solidification experiments.

\subsection{Results and Discussion}

2.3.1. Melting-Solidification Experiments. Figure 2 shows the thermal analysis curves of the acetamide- $\mathrm{SiO}_{2}$ samples. The percentage in the figure's legends represents the mass fraction of $\mathrm{SiO}_{2}$ in samples. All samples were melted at $78^{\circ} \mathrm{C}$ in the heating process. In cooling process, some of the curves exhibited two fluctuations in temperature, the first of which was nucleation and the second was grain boundaries adjustment. Between these two fluctuations, there was a flat region which was the crystal nuclei growth. It can be seen that the supercooling of acetamide existed not only in the beginning of nucleation but also in crystal growth process. In this experiment, supercooling degree of pure acetamide in nucleation and crystal growth process was 14 and $11^{\circ} \mathrm{C}$, respectively.

The solidification temperature of the acetamide- $0.5 \mathrm{wt} . \%$ $\mathrm{SiO}_{2}$ sample was less than that of pure acetamide, as can be seen in Figure 2(a). This reflected the fact that when the content of $\mathrm{SiO}_{2}$ was too short (0.5 wt.\%), the $\mathrm{SiO}_{2}$ could not work as a nucleator, and they would work as an impurity, hindering the crystallization process of the PCM. With the increase in thermal cycles, the cooling curves of the two samples became consistent, indicating that the $\mathrm{SiO}_{2}$ had failed to cause any reaction, as shown in Figures 2(b) and 2(c).

As shown, 1 wt. $\%, 2$ wt. $\%$, and 5 wt. $\% \mathrm{SiO}_{2}$ particles appeared to eliminate the supercooling of acetamide in the initial few cycles. This indicated that the supercooling of acetamide could be eliminated with moderate content of $\mathrm{SiO}_{2}$. However, the supercooling of the acetamide- $1 \mathrm{wt} . \%$ $\mathrm{SiO}_{2}$ gradually increased with the increase of the cycle numbers as shown in Figure 2(b). At the end of the cycles, the cooling curve of the acetamide- 1 wt. $\% \mathrm{SiO}_{2}$ sample was close to that of pure acetamide and the supercooling of the acetamide- $5 \mathrm{wt} . \% \mathrm{SiO}_{2}$ sample also increased slightly. Only the $2 \mathrm{wt} . \% \mathrm{SiO}_{2}$ appeared to efficiently suppress the supercooling during all the cycles; the performance showed almost no change after 50 cycles, indicating that the performance of the acetamide- $2 \mathrm{wt} . \% \mathrm{SiO}_{2}$ sample is the most stable.

Figure 3 shows the thermal analysis curves of the acetamide- $\mathrm{SiO}_{2}$-graphite foam samples. In Figure 3(a), it can be seen that the sample began to crystallize at $65^{\circ} \mathrm{C}$ and that the temperature of crystal nuclei growth was $67^{\circ} \mathrm{C}$. The fluctuations seen in the $2 \%$ and $5 \%$ curves which indicated a sudden increase to the melting temperature were caused by grain boundaries adjustment. Notably, the melting temperature of the samples in which grain boundaries adjustment occurred upon cooling was normal $\left(78^{\circ} \mathrm{C}\right)$ while the others were reduced to $67^{\circ} \mathrm{C}$ as can be seen in Figures 3(a), 3(b), and 


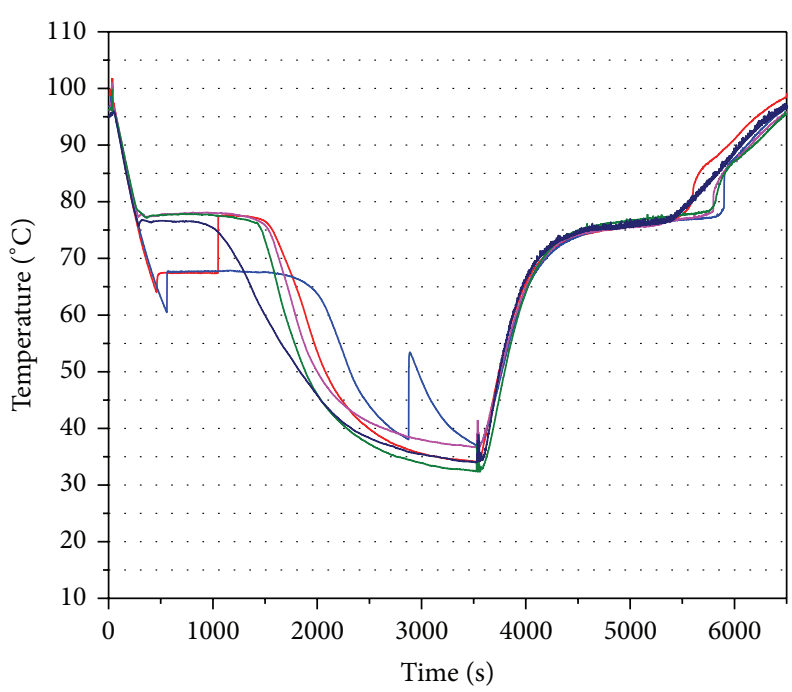

(a)

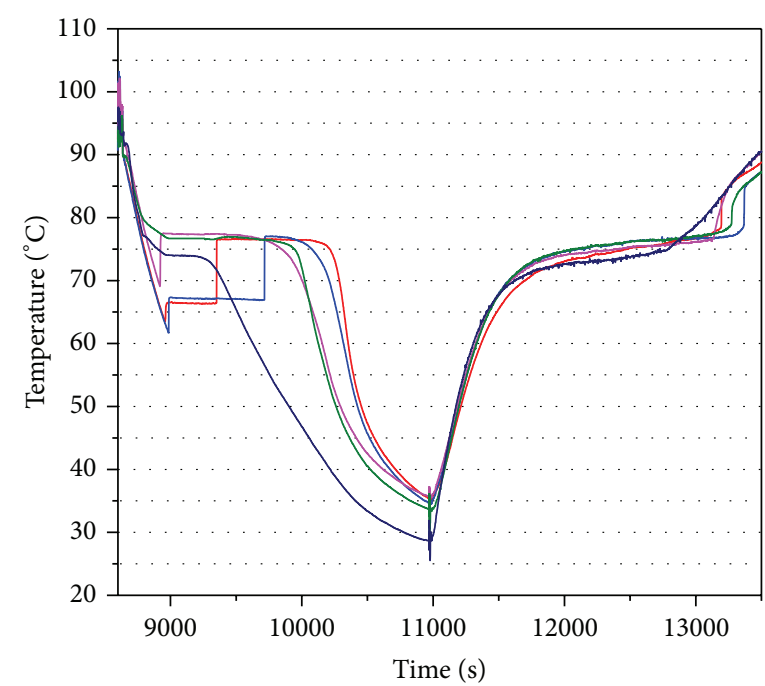

(b)

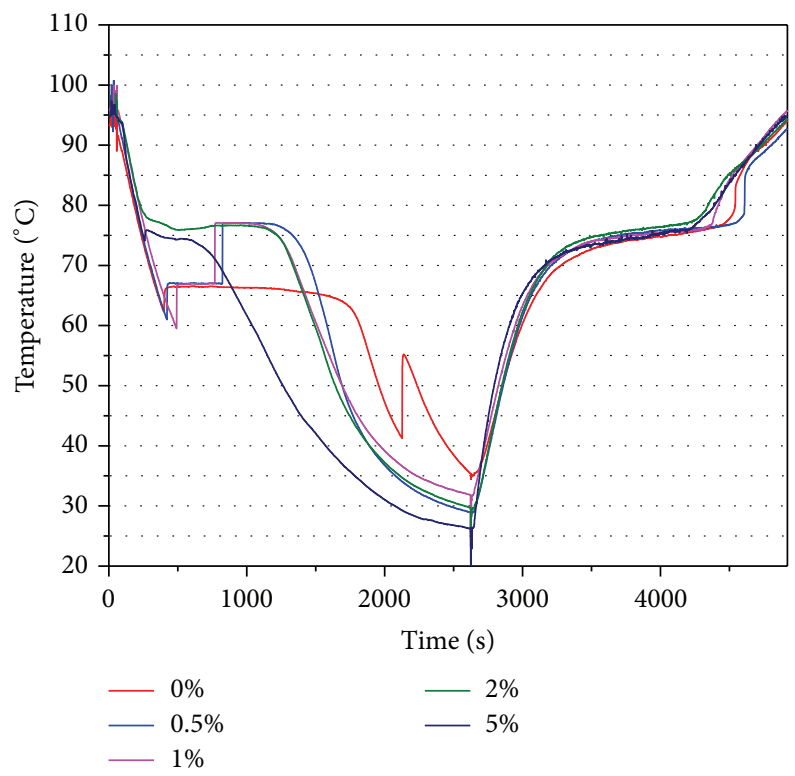

(c)

FIgURE 2: Time-temperature curves of acetamide- $\mathrm{SiO}_{2}$ samples: (a) 1st cycle; (b) 25th cycle; (c) 50th cycle.

3(c). During the first three cycles, the occurrence of the grain boundaries adjustment is random. With the increase in the number of cycles, from the forth cycle to the end, the curves no longer reflect boundaries adjustment. The solidification temperature and melting temperature of samples were $65^{\circ} \mathrm{C}$ and $67^{\circ} \mathrm{C}$, respectively, so that the supercooling of the samples was essentially eliminated. The addition of $\mathrm{SiO}_{2}$ particles produced no apparent effect on the melting-solidification properties of the acetamide- $\mathrm{SiO}_{2}$-graphite foam samples.

In the solidification process, acetamide generated a large number of grain boundaries. Part of the energy released by the solidification was preserved in the grain boundaries so that solidification latent heat would be reduced [11]. The grain boundaries could be reduced by spontaneous adjustment which would allow further the energy release. But the pore structure of the graphite foam severely limited grain boundaries adjustment precluding reduction in the number of grain boundaries. The chemical potential energy stored in the molecular van der Waals attractions is a major factor in the latent energy of materials [12]. A large number of grain boundaries would reduce the intermolecular forces (van der Waals force) that the materials need to overcome during the melting process, so that the melting temperature and latent heat are reduced. This is the reason why the melting point of acetamide- $\mathrm{SiO}_{2}$-graphite foam was lower than normal $\left(78^{\circ} \mathrm{C}\right)$. These conclusions can be confirmed by DSC results.

2.3.2. DSC Results. Figure 4 shows the DSC results for the acetamide and acetamide- $1 \mathrm{wt} . \% \mathrm{SiO}_{2}$ samples. In the DSC 


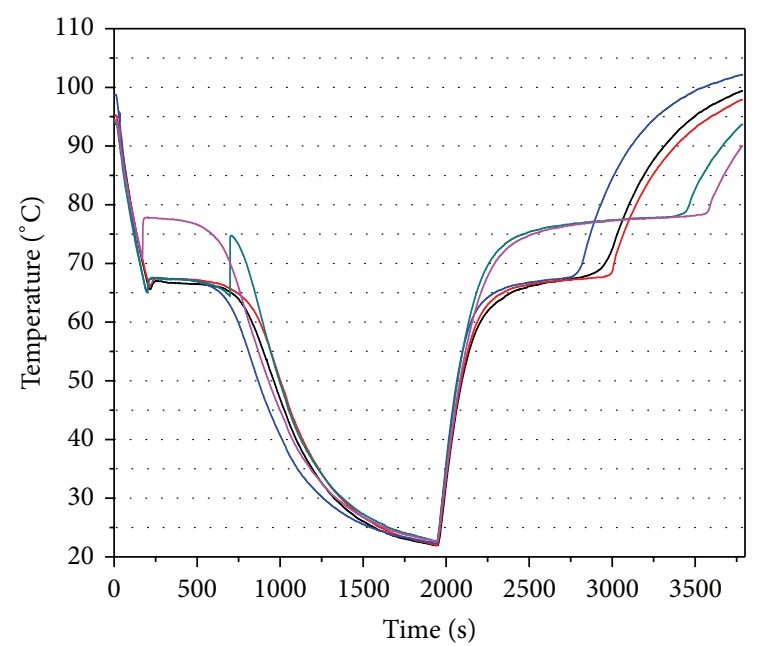

(a)

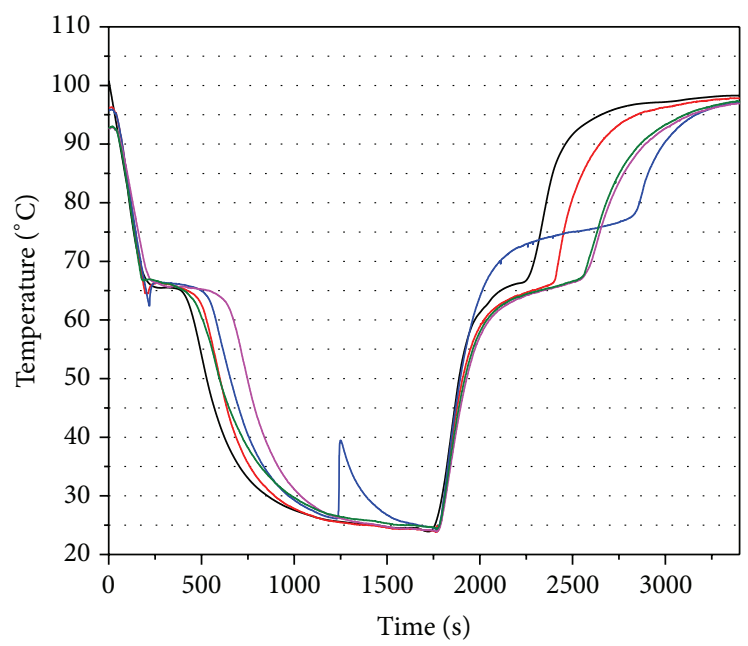

(c)

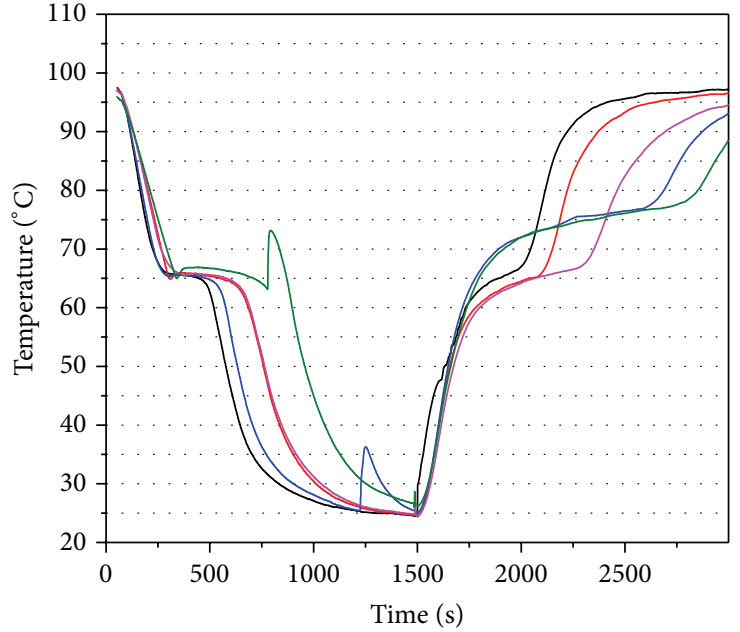

(b)

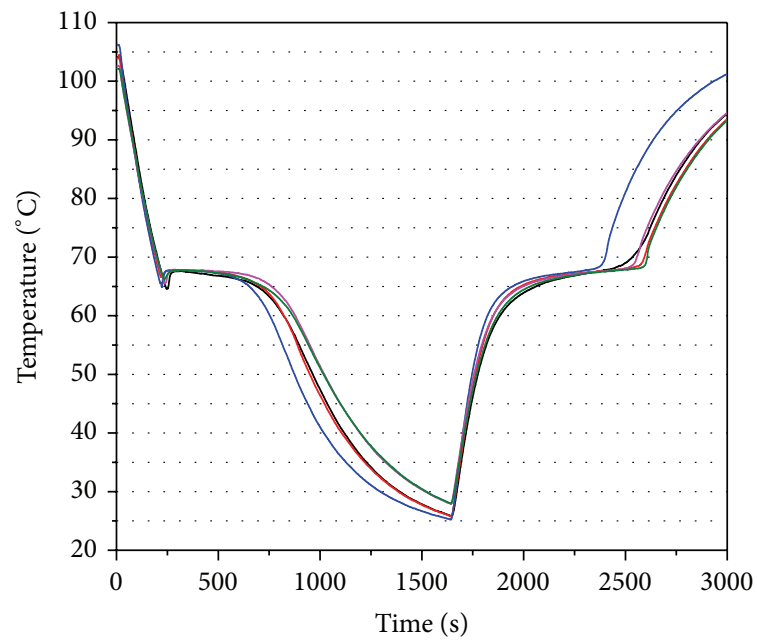

(d)
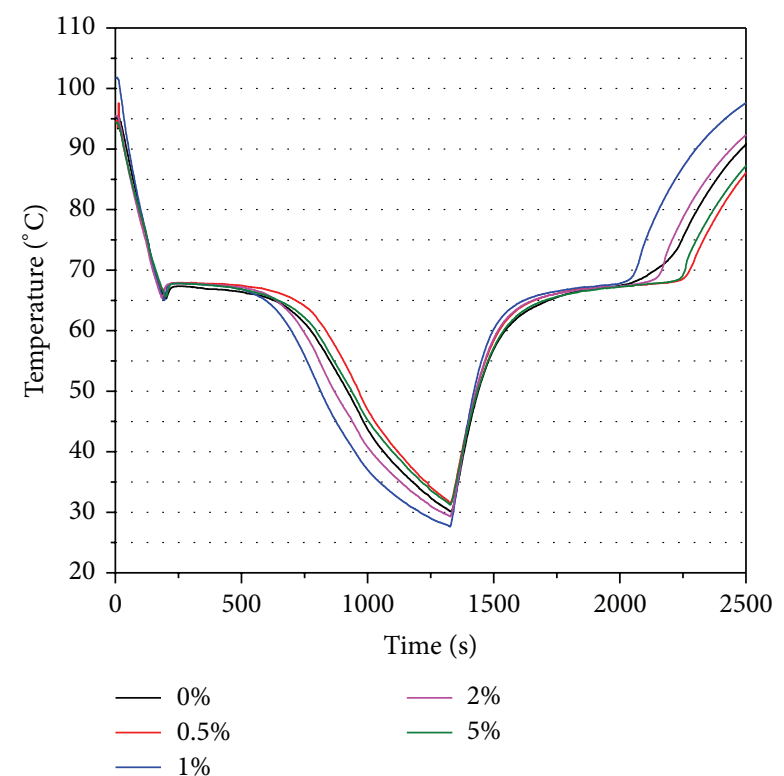

(e)

FiguRE 3: Time-temperature curves of acetamide-SiO ${ }_{2}$-graphite foam samples: (a) 1st cycle; (b) 2nd cycle; (c) 3rd cycle; (d) 4th cycle; (e) 50th cycle. 
TABLE 1: The DSC results of acetamide- $\mathrm{SiO}_{2}$ samples.

\begin{tabular}{lcccc}
\hline Samples & Melting point $\left({ }^{\circ} \mathrm{C}\right)$ & Solidification point $\left({ }^{\circ} \mathrm{C}\right)$ & Melting latent heat $/\left(\mathrm{J} \cdot \mathrm{g}^{-1}\right)$ & Solidification latent heat $\left(\mathrm{J} \cdot \mathrm{g}^{-1}\right)$ \\
\hline $0 \%$ & 80.3 & 41 & 280.3 & 224.1 \\
$0.5 \%$ & 79.8 & 39.5 & 278.6 & 219.8 \\
$1 \%$ & 79.8 & 72.1 & 278.2 & 270.5 \\
$2 \%$ & 79.9 & 70.9 & 272.6 & 266.8 \\
$5 \%$ & 79.8 & 57.6 & 270 & 248.2 \\
\hline
\end{tabular}

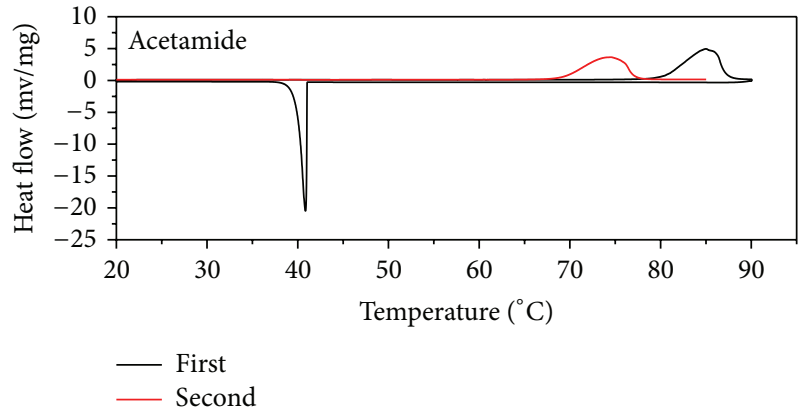

(a)

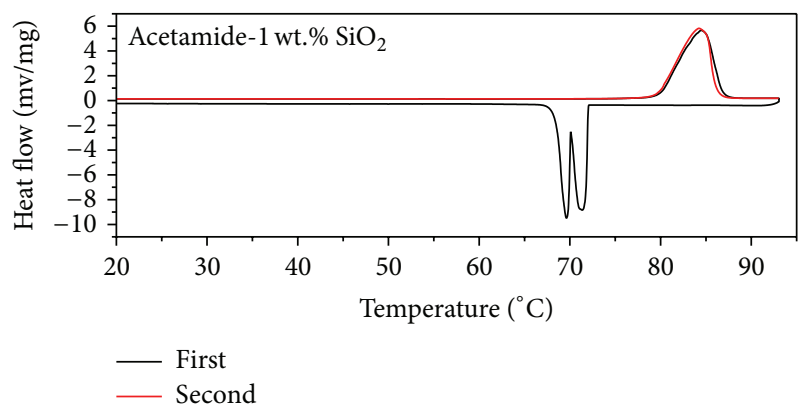

(b)

Figure 4: DSC curves of acetamide and acetamide-1wt.\% $\mathrm{SiO}_{2}$ samples: (a) acetamide; (b) acetamide- $1 \mathrm{wt} . \% \mathrm{SiO}_{2}$.

curve of acetamide sample, the first melting, first solidification, and second melting temperatures were $80.3^{\circ} \mathrm{C}, 41^{\circ} \mathrm{C}$, and $69.2^{\circ} \mathrm{C}$ and the corresponding latent heat was $280.3 \mathrm{Jg}^{-1}$, $204.1 \mathrm{Jg}^{-1}$, and $223.5 \mathrm{Jg}^{-1}$, respectively. As can be seen, the latent heat of solidification was much smaller than that of melting, indicating that the grain boundaries were not adjusted, so that the second melting temperature was lower than the first. The solidification temperatures and latent heat of the acetamide- $1 \mathrm{wt} . \% \mathrm{SiO}_{2}$ sample were $72.1^{\circ} \mathrm{C}$ and $270.5 \mathrm{~J}$ $\cdot \mathrm{g}^{-1}$, showing that the $\mathrm{SiO}_{2}$ particles reduced the degree of supercooling and the number of grain boundaries so that more latent heat was released and the second melting curve is consistent with the first.

The DSC results of acetamide- $\mathrm{SiO}_{2}$ samples are given in Table 1 and Figure 5. The supercooling of $0 \%, 0.5 \%, 1 \%, 2 \%$, and $5 \%$ samples occurred at $39.3^{\circ} \mathrm{C}, 40.3^{\circ} \mathrm{C}, 7.7^{\circ} \mathrm{C}, 9.0^{\circ} \mathrm{C}$, and $22.2^{\circ} \mathrm{C}$ and the solidification enthalpies for these events were $56.2 \mathrm{~J} \cdot \mathrm{g}^{-1}, 58.8 \mathrm{~J} \cdot \mathrm{g}^{-1}, 7.7 \mathrm{~J} \cdot \mathrm{g}^{-1}, 5.8 \mathrm{~J} \cdot \mathrm{g}^{-1}$, and $21.8 \mathrm{~J} \cdot \mathrm{g}^{-1}$ which are each lower than the melting latent heat. The larger

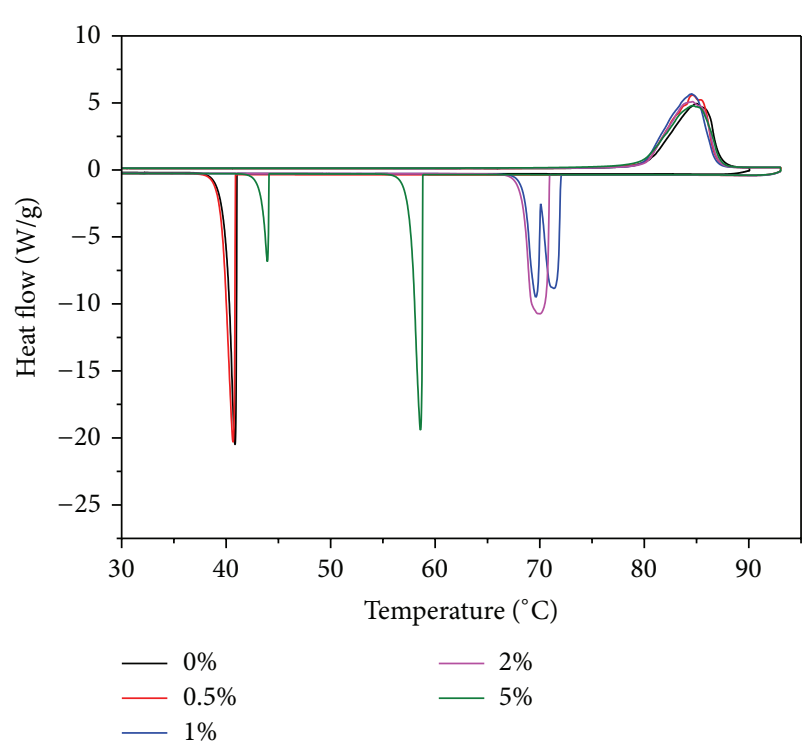

FIGURE 5: DSC curves of acetamide- $\mathrm{SiO}_{2}$ samples.

supercooling and smaller solidification latent heat of the $0 \%$ and $0.5 \%$ samples indicate that no effective grain boundaries adjustment had occurred. In contrast, $1 \%$ and $2 \%$ samples which exhibited smaller supercooling and larger solidification enthalpies indicated that these samples had fewer grain boundaries. The process of grain boundaries adjustment could be seen in the cooling curve of the 5\% sample, which possessed two exothermic peaks. One peak was associated with nucleation with a latent heat of $200 \mathrm{~J} \cdot \mathrm{g}^{-1}$ and the other was indicative of grain boundaries adjustment with a latent heat of $48.18 \mathrm{~J} \cdot \mathrm{g}^{-1}$.

Notably, the sample quantities used for the DSC and melting-solidification experiments were $5 \mathrm{mg}$ and $10 \mathrm{~g}$, respectively. The degree of the supercooling decreased when the mass of the specimen was increased from $5 \mathrm{mg}$ to $10 \mathrm{~g}$. This could be due to the increase in the nucleation catalyst in molten acetamide as a result of the increase in the mass of the specimen [13]. Therefore, the supercooling measured by DSC was the extreme case and the results of cycling experiment were more in line with the actual applications.

\section{Simulation Study}

3.1. Classical Nucleation Theory. The traditional theory of nucleation $[14,15]$ is based on the Gibbs theory [16] which is described as the generation of new phase within a uniform 


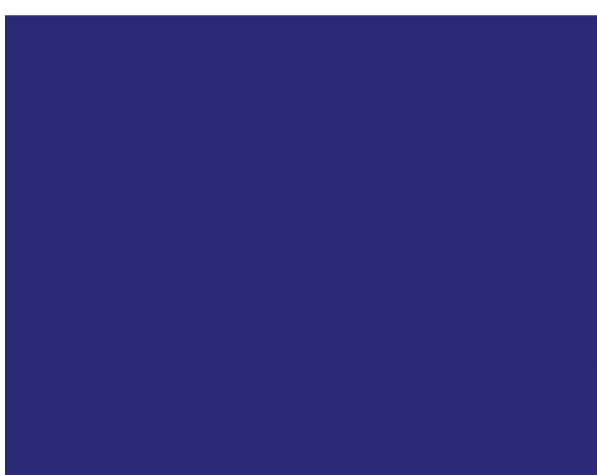

(a)

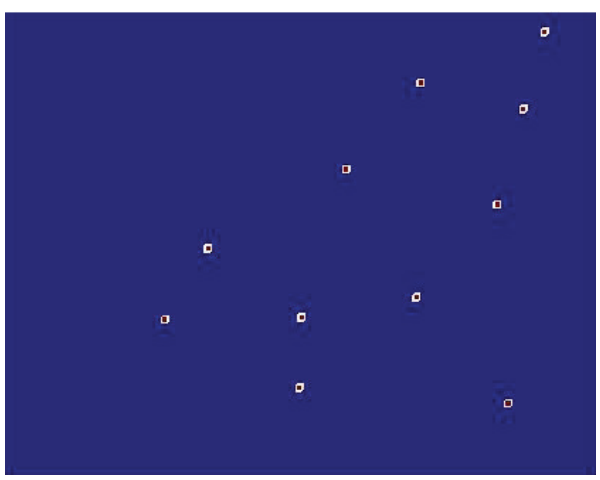

(c)

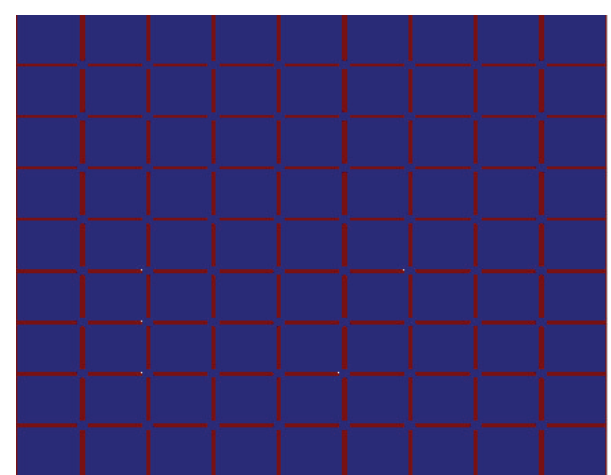

(b)

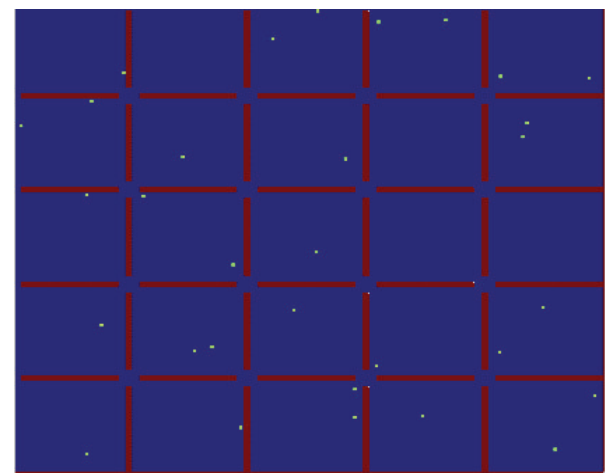

(d)

FIGURE 6: The initial state of different samples in simulations: (a) acetamide; (b) acetamide-graphite foam; (c) acetamide-SiO ${ }_{2}$; (d) acetamide$\mathrm{SiO}_{2}$-graphite foam.

single-phase system. We have successfully employed this theory to explain many of the experiments phenomena.

The surface free energy of spherical particles is

$$
\Delta F_{s}=4 \pi r^{2} \sigma
$$

$\Delta F_{s}$ is the change of surface free energy; $\sigma$ is solid and liquid interface energy. The solid-liquid phase change process provides the change of free energy, for spherical particles; that is,

$$
\Delta F_{V}=-\frac{4}{3} \pi r^{3} \Delta F_{v}
$$

where $\Delta F_{V}$ is the free energy change with the formation of a new phase; $\Delta F_{v}$ is the free energy change with the formation of a new phase per unit volume. For spherical particles, the change of net free energy is

$$
\Delta F=4 \pi r^{2} \sigma-\frac{4}{3} \pi r^{3} \Delta F_{v}
$$

$\Delta F$ reaches a maximum value at $r_{k}$, where $r_{k}$ is the critical radius of the crystal nuclei. For a spontaneous process, the free energy is always reduced. When the size of the grain is smaller than the critical size, the grains are melted on their own; when the grain size is greater than the critical size, the crystal nuclei will grow spontaneously. Calculating the derivative of (3), the critical radius of the spherical particles is obtained when the $\Delta F$ is maximum:

$$
r_{k}=\frac{2 \sigma}{\Delta F_{v}} .
$$

$\Delta F_{v}$ is proportional to the supercooling:

$$
\Delta F_{v}=\alpha \Delta T
$$

where $\alpha$ is a constant and the $\Delta T$ is the degree of supercooling. Placing (5) into (4), we obtain

$$
r_{k}=\frac{2 \sigma}{\alpha \Delta T}
$$

It is clear that as $\Delta T$ increases, $r_{k}$ will decrease and nucleation will be facilitated.

The nucleation process also includes heterogeneous nucleation. Heterogeneous nucleation occurs on the surface of other materials, such as impurity particles or vessel bumps. The degree of supercooling by heterogeneous nucleation is very small. In this paper, the additives of $\mathrm{SiO}_{2}$ were assumed to be the heterogeneous grain, prompting acetamide heterogeneous nucleation, which significantly reduced the degree of supercooling.

3.2. Solidification Simulation. Based on the classic nucleation theory, the solidification process of acetamide, acetamide$\mathrm{SiO}_{2}$, acetamide-graphite foam, and acetamide- $\mathrm{SiO}_{2}$-graphite 
foam samples was simulated using MATLAB software. The simulation used a matrix of $1000 * 1000$ to represent the samples. In this matrix, the numbers 0,1 , and 2 represented the liquid samples, the solid samples, and the graphite foam skeleton, respectively. The different crystal nuclei used different numbers which are greater than 2 . The crystal nuclei radius is represented by the number of connected "solid" nodes; the critical radius of the crystal nuclei was represented by $A / \Delta T$, where $A$ is a constant obtained by comparing the simulated and DSC results and $\Delta T$ is the degree of supercooling. The so-called "crystal nuclei" is the general term used for connected "solid" nodes whose number is larger than the critical size. In the large $1000 * 1000$ matrix, several small matrices with sizes of $4 * 4$ were randomly selected to simulate the $\mathrm{SiO}_{2}$ particles randomly dispersed in acetamide.

Figure 6 was the initial states of simulation in various cases. The schematic of molten acetamide, acetamidegraphite foam, acetamide- $\mathrm{SiO}_{2}$, and acetamide- $\mathrm{SiO}_{2}$ graphite foam was shown in Figures 6(a)-6(d), respectively. In Figure 6(b), the gray frame represents the graphite foam skeleton, the entire sample was divided into 100 cells by "skeleton," and all cells were in communication with each other just like the interconnected pores of graphite foam. In Figure 6(c), the white point was $\mathrm{SiO}_{2}$ particles, one hundred randomly distributed " $\mathrm{SiO}_{2}$ particles" were throughout the whole region. This figure was a partially enlarged view. In Figure 6(d), the sample was divided into 100 cells by "graphite foam skeleton" and one hundred randomly distributed " $\mathrm{SiO}_{2}$ particles" throughout the whole region; this figure is a partially enlarged diagram.

The rules of the program were as follows: (1) if the state of the node was "graphite foam," " $\mathrm{SiO}_{2}$ " or "crystal nuclei," then it remained unchanged; (2) if (1) was false and a "crystal nuclei" was adjacent to the node, then the state changed to the "crystal nuclei"; (3) if (1) and (2) were false, the node could change to "solid" with the probability of $P$ and with the probability of $1-P$ into "liquid."

The main program flow chart is shown in Figure 7.

3.3. Results and Discussion. In the simulations, the supercooling degree of four samples was $39.20^{\circ} \mathrm{C}, 40.02^{\circ} \mathrm{C}, 9.10^{\circ} \mathrm{C}$, and $10.20^{\circ} \mathrm{C}$ in turn. It can be seen that $\mathrm{SiO}_{2}$ significantly reduced the degree of supercooling; the crystal nuclei of acetamide- $\mathrm{SiO}_{2}$ and acetamide- $\mathrm{SiO}_{2}$-graphite foam samples were generated by heterogeneous nucleation on the surface $o$ $\mathrm{f} \mathrm{SiO}_{2}$ particles.

In Figures 8 and 9, the samples had many crystal nuclei and grain boundaries with a large degree of supercooling. After adding the graphite foam, many grain boundaries were forcibly separated by the graphite foam skeleton, increasing the total number of grain boundaries. Moreover, the grain boundaries which were separated by the graphite foam skeleton could not be eliminated by grain boundaries adjustment. This part of the grain boundaries was termed "permanent grain boundaries." Figures 10 and 11 show that the number of crystal nuclei and grain boundaries was significantly reduced by $\mathrm{SiO}_{2}$ particles, but the presence of the graphite foam still produced large numbers of grain boundaries.

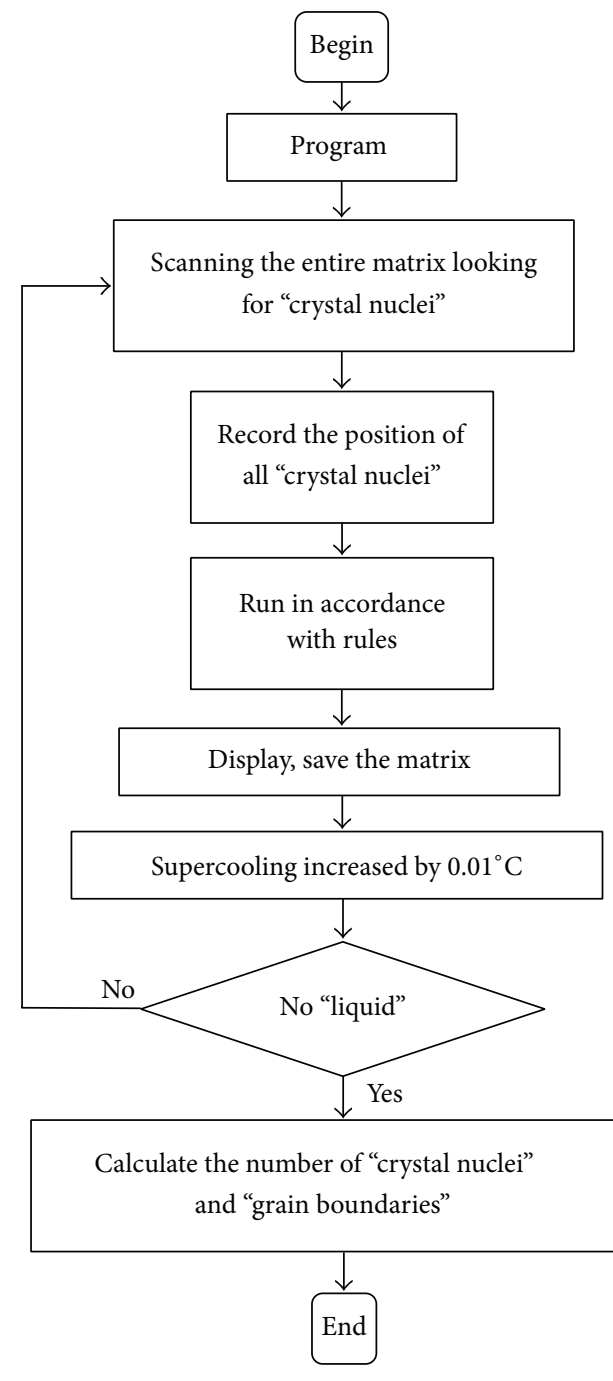

FIGURE 7: The main program flow chart.

Table 2 lists the number of grain boundaries and the crystal nuclei in the simulations. Acetamide had many grain boundaries, so that grain boundaries adjustment was difficult and the heat release was small. The total numbers of crystal nuclei and grain boundaries of the acetamide- $\mathrm{SiO}_{2}$ were the least so that the more heat was released, which was consistent with the DSC results (refer to Figure 4). In the simulation of acetamide-graphite foam and acetamide- $\mathrm{SiO}_{2}$-graphite foam samples, the grain boundaries were more complex and difficult to adjust, due to the presence of graphite foam, which was consistent with the conclusion of the melting-solidification experiments (see Figure 5).

\section{Conclusions}

Acetamide- $\mathrm{SiO}_{2}$ composite has been prepared, by adding $\mathrm{SiO}_{2}$ particles to acetamide and this composite was then impregnated into the graphite foam to form a new type of 


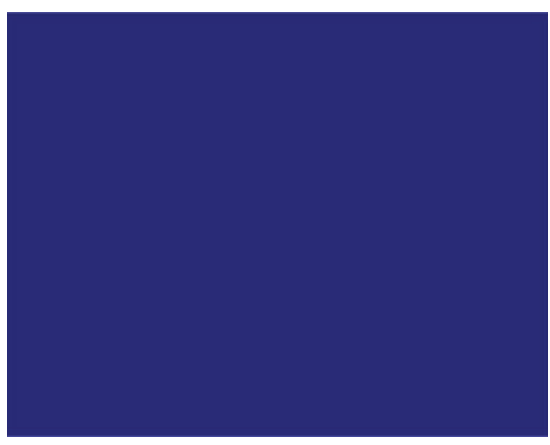

(a)

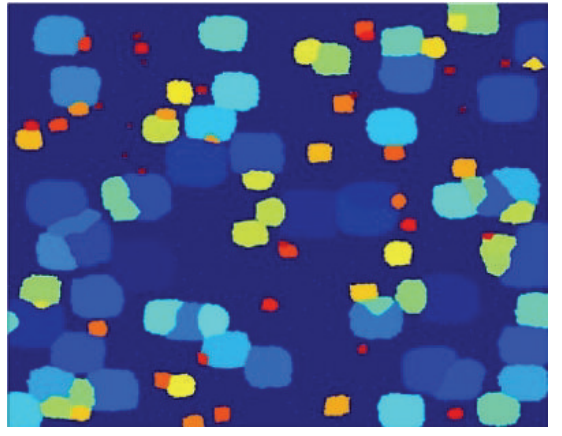

(b)

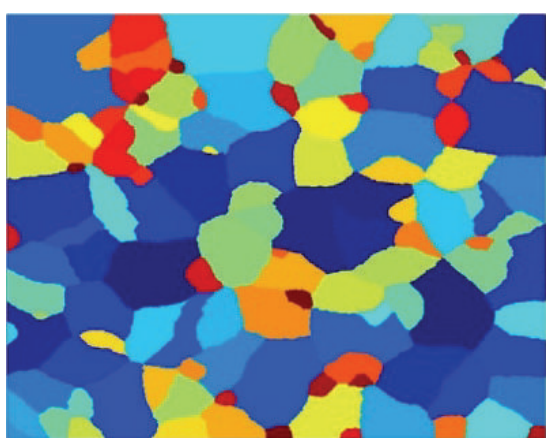

(c)

FIGURE 8: Acetamide crystallization simulation: (a) the initial state; (b) being crystallization; (c) crystallization completed.

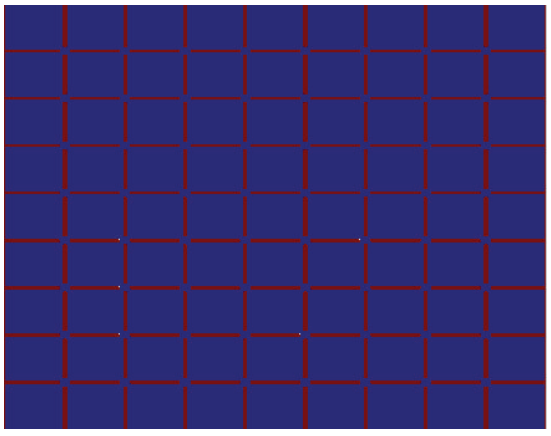

(a)

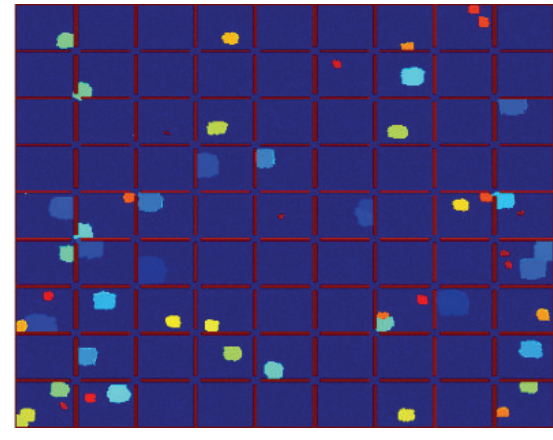

(b)

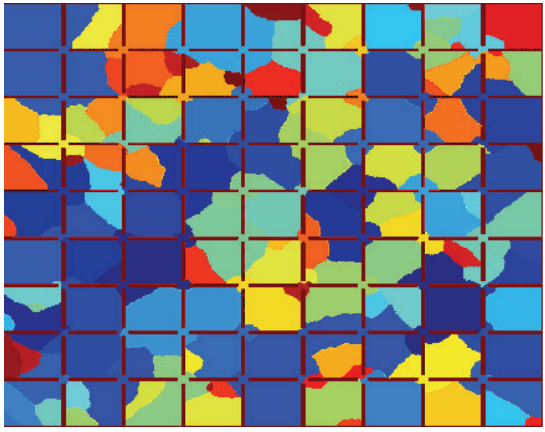

(c)

FIGURE 9: Acetamide-graphite foam crystallization simulation: (a) the initial state; (b) being crystallization; (c) crystallization completed.

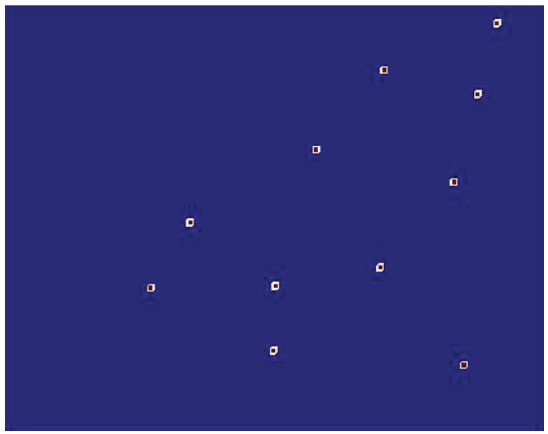

(a)

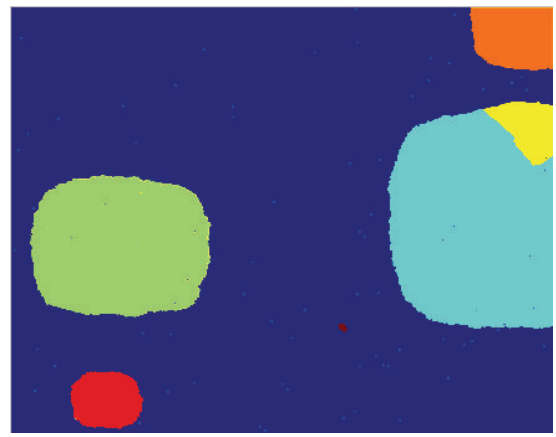

(b)

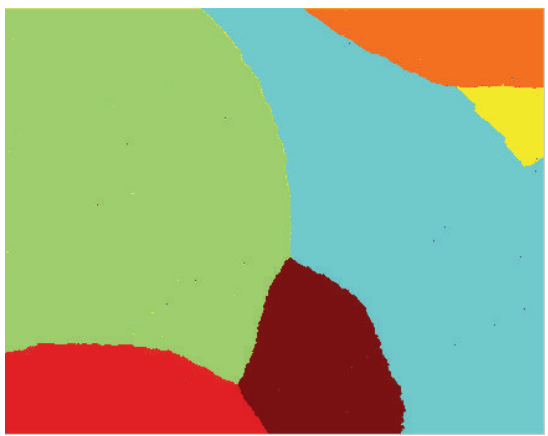

(c)

FIGURE 10: Acetamide-SiO ${ }_{2}$ crystallization simulation: (a) the initial state; (b) being crystallization; (c) crystallization completed.

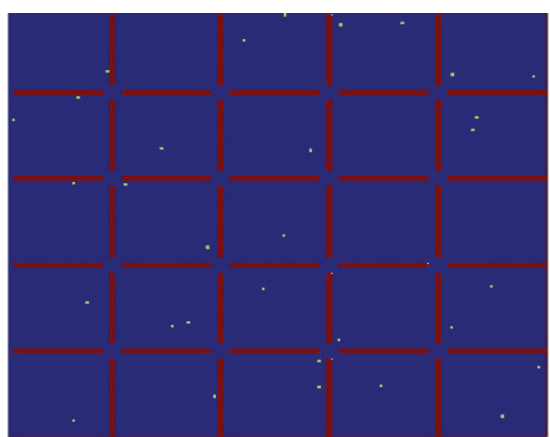

(a)

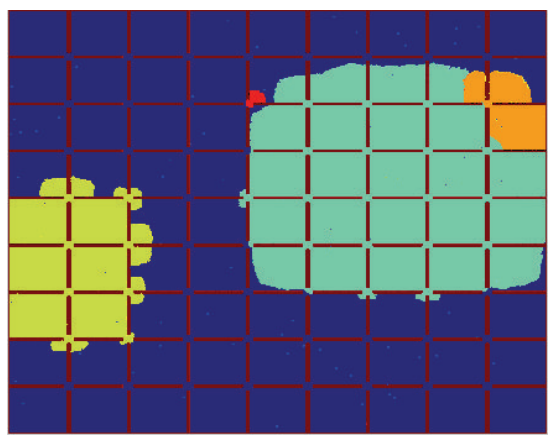

(b)

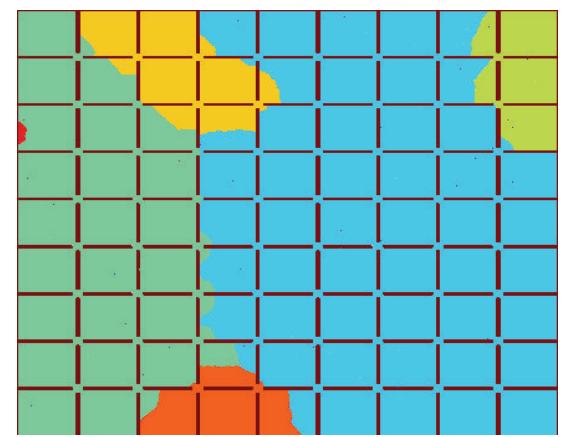

(c)

FIgURE 11: Acetamide- $\mathrm{SiO}_{2}$-graphite foam crystallization simulation: (a) the initial state; (b) being crystallization; (c) crystallization completed. 
TABLE 2: The number of crystal nuclei and grain boundaries in the simulation.

\begin{tabular}{lccc}
\hline Samples & The numbers of crystal nuclei & Total grain boundaries (node) & Permanent grain boundaries (node) \\
\hline Acetamide & 103 & 21336 & 0 \\
Acetamide-Graphite foam & 98 & 35037 & 17360 \\
Acetamide- $\mathrm{SiO}_{2}$ & 6 & 4303 & 0 \\
Acetamide- $\mathrm{SiO}_{2}$-Graphite foam & 6 & 21300 & 17360 \\
\hline
\end{tabular}

form-stable phase change material. Each sample was subjected to 50 melting-solidification cycles and the acetamide$\mathrm{SiO}_{2}$ samples were tested using DSC. Based on the classical nucleation theory, the crystallization process of these samples was simulated using MATLAB. The conclusions of this work are as follows.

In melting-solidification experiments, the crystallization supercooling degree of acetamide was $14^{\circ} \mathrm{C}$; the supercooling of crystal nuclei growth was $11^{\circ} \mathrm{C}$. The supercooling of acetamide could be eliminated by adding $\mathrm{SiO}_{2}$ with a mass fraction of $1 \%$ to $5 \%$. The performance of the acetamide- $2 \%$ $\mathrm{SiO}_{2}$ was very stable with no change after 50 cycles. The acetamide- $\mathrm{SiO}_{2}$ samples were impregnated into the graphite foam, the melting temperature of the acetamide- $\mathrm{SiO}_{2}$-graphite foam samples was reduced to $67^{\circ} \mathrm{C}$, and the solidification temperature was reduced to $65^{\circ} \mathrm{C}$. At the same time, the supercooling degree of the samples was essentially eliminated, but a little heat storage capacity was lost. The presence of $\mathrm{SiO}_{2}$ did not have a significant impact on the supercooling of these samples.

DSC results showed that the grain boundaries of acetamide could not be effectively adjusted, so that the heat release was low during the cooling process. In the second melting process, the large numbers of boundaries in acetamide caused the melting point and melting latent heat to be lower than normal. Addition of $\mathrm{SiO}_{2}$ with the content of $1 \mathrm{wt} . \%$ and $2 \mathrm{wt} . \%$ reduced the supercooling of acetamide to less than $10^{\circ} \mathrm{C}$ and improved the heat release. In the first and second melting process, the melting points and latent heat of the samples were equal.

The simulation results showed that the presence of $\mathrm{SiO}_{2}$ could significantly reduce the number of grain boundaries. On the contrary, the presence of graphite foam could significantly increase the number of grain boundaries and make the grain boundaries more difficult to adjust. The simulation also explained the reason, from the microscopic point of view, why the degree of supercooling was reduced. This was attributed to be heterogeneous nucleation which occurred along the $\mathrm{SiO}_{2}$ particles in the crystallization process.

\section{Conflict of Interests}

The authors declare that there is no conflict of interests regarding the publication of this paper.

\section{Acknowledgment}

This research work is supported by the National Natural Science Fund of China (Project no. 51102059).

\section{References}

[1] B. Chalmers, Principles of Solidification, John Wiley \& Sons, 1964.

[2] J. D. Hunt and K. A. Jackson, "Nucleation of solid in an undercooled liquid by cavitation," Journal of Applied Physics, vol. 37, no. 1, pp. 254-257, 1966.

[3] J. D. Hunt and K. A. Jackson, "Nucleation of solid in an undercooled liquid by cavitation," Journal of Applied Physics, vol. 37, p. 254, 1966.

[4] T. Wada and R. Ymamoto, "Studies on salt hydrate for latent heat storage. I. Crystal nucleation of sodium acetate trihydrate catalyzed by tetrasodium pyrophosphate decahydrate," Bulletin of the Chemical Society of Japan, vol. 55, pp. 3603-3606, 1982.

[5] S. Mo, Y. Chen, L. Jia, and X. Luo, "Reduction of supercooling of water by $\mathrm{TiO}_{2}$ nanoparticles as observed using differential scanning calorimeter," Journal of Experimental Nanoscience, vol. 8, no. 4, pp. 533-539, 2013.

[6] D.-J. Lu, P. Hu, B.-B. Zhao, Y. Liu, and Z.-S. Chen, "Study on the performance of nanoparticles as nucleating agents for sodium acetate trihydrate," Journal of Engineering Thermophysics, vol. 33, no. 8, pp. 1279-1282, 2012.

[7] X. Wu, Y. Wang, S. Rong et al., "The anti-supercooling effect of surface-modified nano-scaled $\mathrm{SiO}_{2}$ in hydrated salts phase transition system," in Proceedings of the 8th China International Nanoscience and Technology Symposium (CINSTS '09), Journal of Physics: Conference Series 188, 2009.

[8] S. Marks, "An investigation of the thermal energy storage capacity of Glauber's salt with respect to thermal cycling," Solar Energy, vol. 25, no. 3, pp. 255-258, 1980.

[9] K. Lafdi, O. Mesalhy, and A. Elgafy, "Graphite foams infiltrated with phase change materials as alternative materials for space and terrestrial thermal energy storage applications," Carbon, vol. 46, no. 1, pp. 159-168, 2008.

[10] A. Yadav, R. Kumar, G. Bhatia, and G. L. Verma, "Development of mesophase pitch derived high thermal conductivity graphite foam using a template method," Carbon, vol. 49, no. 11, pp. 36223630, 2011.

[11] Z. Renyuan, Phase Change Materials with Phase Change Energy Storage Technology, Science Press, Beijing, China, 2009.

[12] S. Shaikh, K. Lafdi, and K. Hallinan, "Carbon nanoadditives to enhance latent energy storage of phase change materials," Journal of Applied Physics, vol. 103, no. 9, Article ID 094302, 2008.

[13] L. Wei and K. Ohsasa, "Supercooling and solidification behavior of phase change material," ISIJ International, vol. 50, no. 9, pp. 1265-1269, 2010.

[14] M. Volmer and H. Flood, "Tröpfchenbildung in Dämpfen," Zeitschrift fur Physikalische Chemie. Abteilung A, vol. 170, p. 273, 1934. 
[15] M. Volmer, Kinetics der Phasenbildung, Theodor Steinkopff, Dresden, Germany, 1939.

[16] J. W. Gibbs, The Collected Works of J. Willard Gibbs, Yale University Press, New Haven, Conn, USA, 1957. 

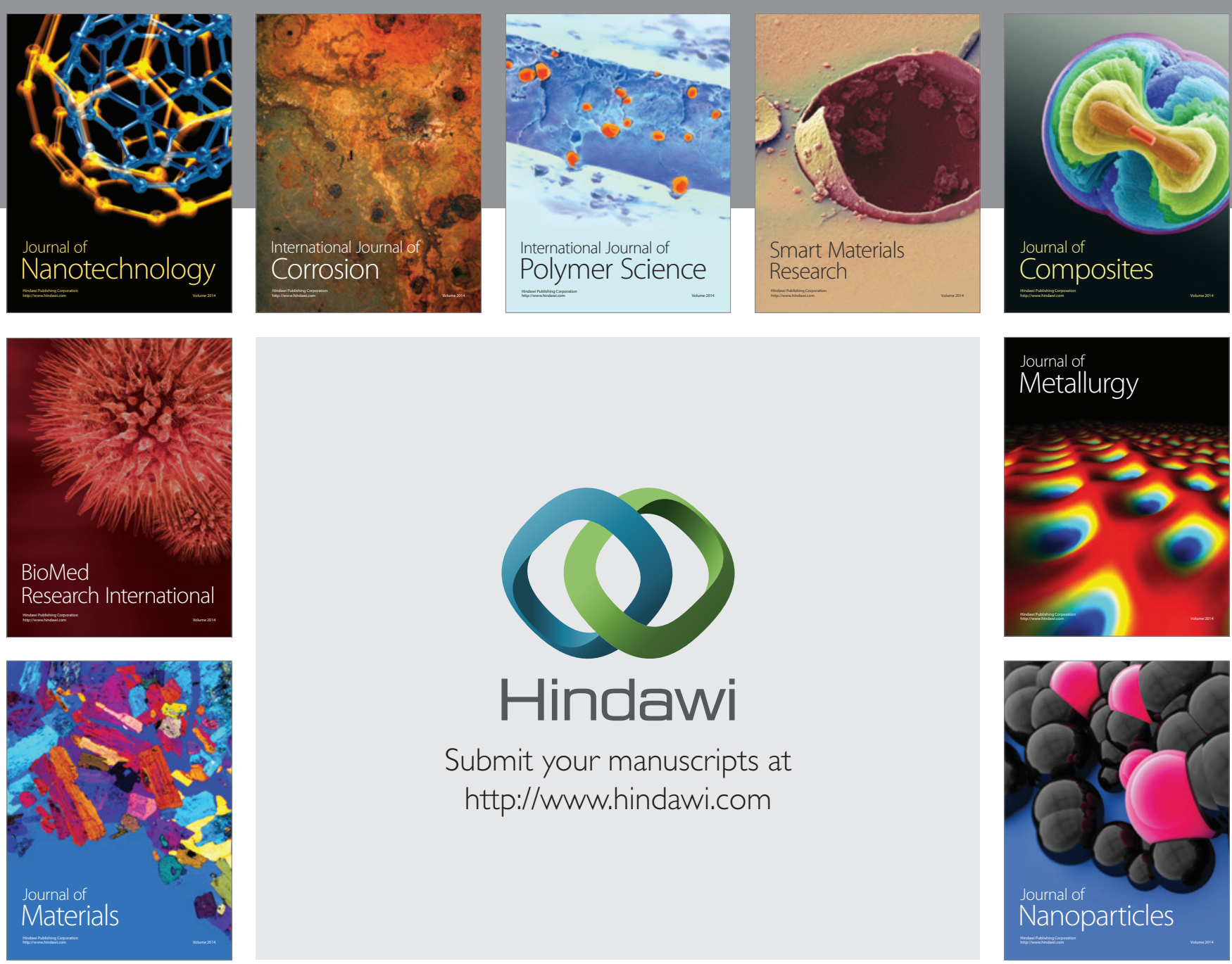

Submit your manuscripts at http://www.hindawi.com
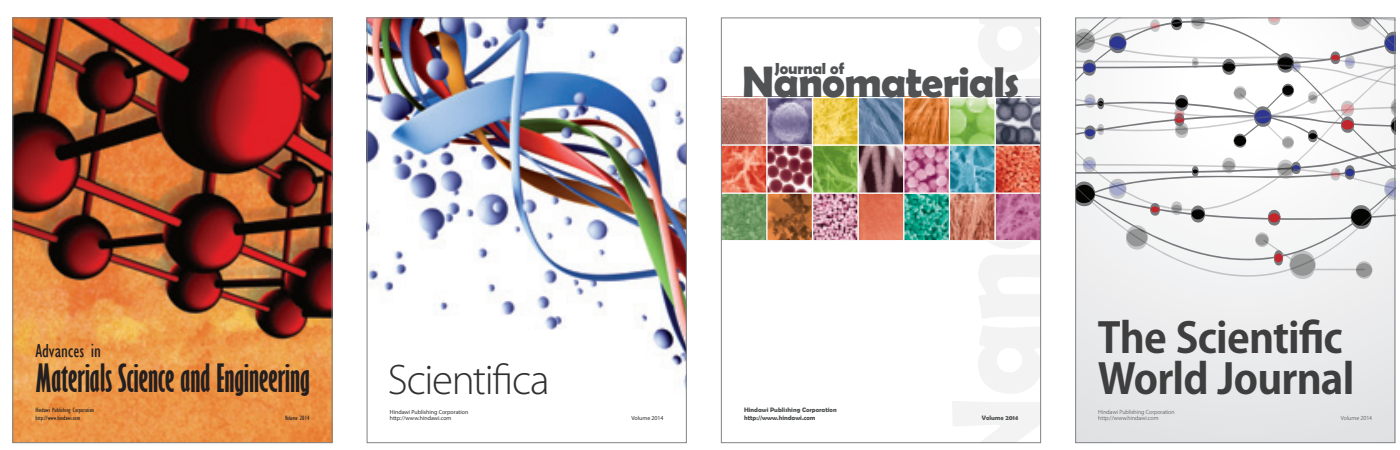

\section{The Scientific World Journal}
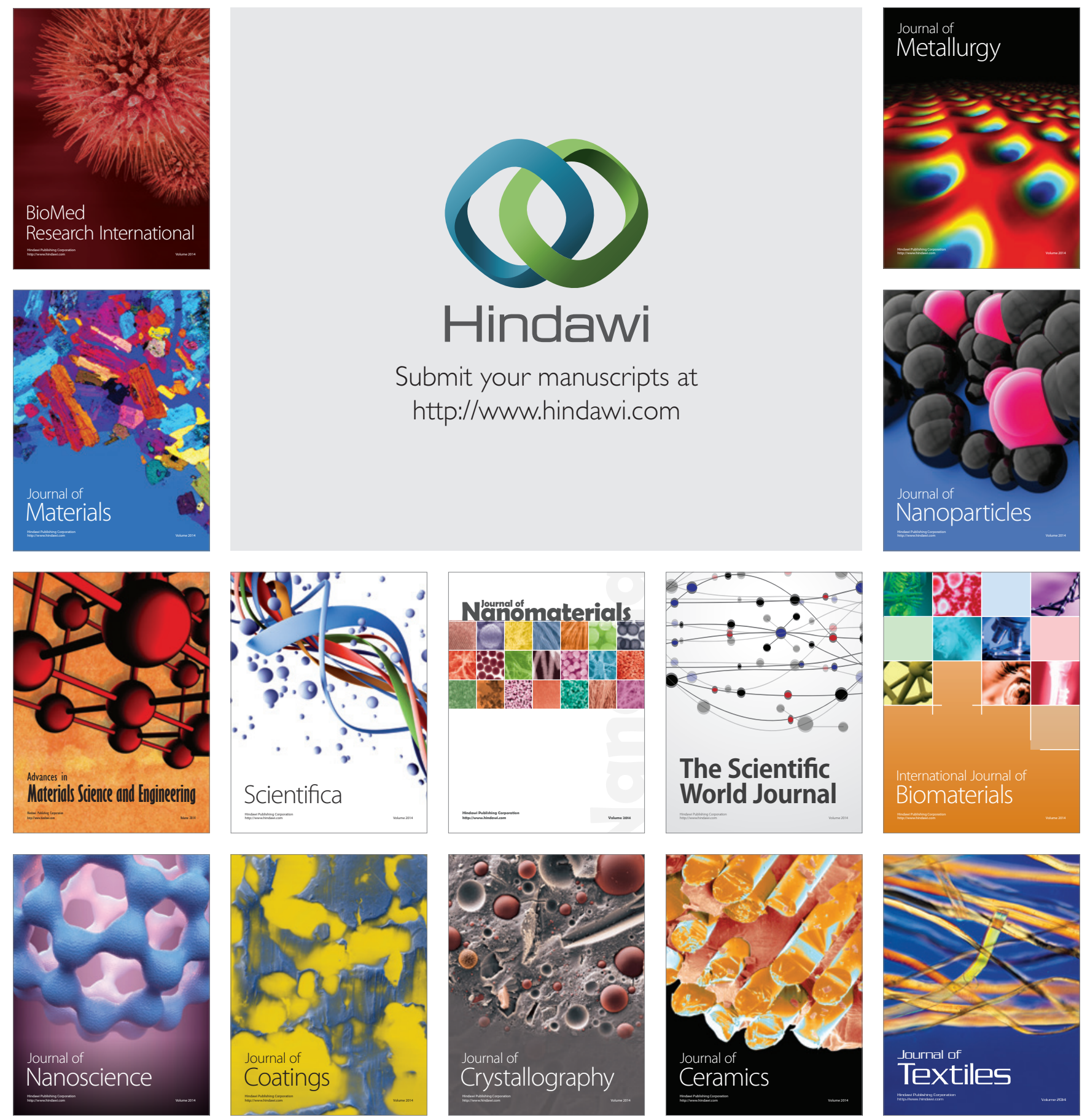